\title{
Iron suppresses erythropoietin expression via oxidative stress-dependent hypoxia-inducible factor-2 alpha inactivation
}

\author{
Keisuke Oshima ${ }^{1,2,9}$, Yasumasa Ikeda ${ }^{1,9}$, Yuya Horinouchi ${ }^{1}$, Hiroaki Watanabe ${ }^{3}$, Hirofumi Hamano ${ }^{1,4}$, Yoshitaka Kihira ${ }^{1,5}$, \\ Seiji Kishi ${ }^{6}$, Yuki Izawa-Ishizawa', Licht Miyamoto7, Tasuku Hirayama ${ }^{8}$, Hideko Nagasawa ${ }^{8}$, Keisuke Ishizawa ${ }^{3,4}$, \\ Koichiro Tsuchiya ${ }^{7}$ and Toshiaki Tamaki ${ }^{1}$
}

Renal anemia is a major complication in chronic kidney disease (CKD). Iron supplementation, as well as erythropoiesisstimulating agents, are widely used for treatment of renal anemia. However, excess iron causes oxidative stress via the Fenton reaction, and iron supplementation might damage remnant renal function including erythropoietin (EPO) production in CKD. EPO gene expression was suppressed in mice following direct iron treatment. Hypoxia-inducible factor2 alpha (HIF-2a), a positive regulator of the EPO gene, was also diminished in the kidney of mice following iron treatment. Anemia-induced increase in renal EPO and HIF-2a expression was inhibited by iron treatment. In in vitro experiments using EPO-producing HepG2 cells, iron stimulation reduced the expression of the EPO gene, as well as HIF-2a. Moreover, iron treatment augmented oxidative stress, and iron-induced reduction of EPO and HIF-2a expression was restored by tempol, an antioxidant compound. HIF-2a interaction with the Epo promoter was inhibited by iron treatment, and was restored by tempol. These findings suggested that iron supplementation reduced EPO gene expression via an oxidative stress-HIF-2adependent signaling pathway.

Laboratory Investigation (2017) 97, 555-566; doi:10.1038/labinvest.2017.11; published online 6 March 2017

The incidence of chronic kidney disease (CKD) has increased worldwide, and CKD worsens morbidity and mortality in the general population. ${ }^{1,2}$ The progression of CKD results in endstage renal failure, which requires treatment by hemodialysis or renal transplantation. In addition, a variety of complications arises during the course of CKD. Cardiovascular disease, a major complication of $\mathrm{CKD}$, also leads to worse outcomes in CKD patients. ${ }^{3}$ Renal anemia is commonly seen in individuals with CKD due to insufficient erythropoietin (EPO) production within the diseased kidney. ${ }^{4,5}$ Therefore, patients with end-stage renal disease receive erythropoiesisstimulating agent (ESA) for the treatment of renal anemia.

Iron supplementation, in addition to ESA, is often used for the treatment of renal anemia. ${ }^{6}$ However, patients with CKD often show functional iron deficiency, rather than absolute iron deficiency, characterized by impaired iron release from body iron stores. ${ }^{7}$ Disturbance of iron utilization in CKD occurs due to ferroportin (a cellular iron exporter) degradation resulting from increased hepcidin production. ${ }^{8,9}$ Hepcidin is positively controlled by iron stores. ${ }^{10}$ Therefore, iron treatment further exacerbates impaired iron utilization via hepcidin elevation and results in over accumulation of disused iron in organs of CKD individuals. Actually, adverse effects of iron supplementation on organs have been directly observed in several studies. Iron sucrose treatment exacerbates endothelial dysfunction in healthy subjects ${ }^{11}$ and atherosclerotic change through enhancement of oxidative stress in a CKD mouse model. ${ }^{12}$ Intravenous iron also causes

'Department of Pharmacology, Institute of Biomedical Sciences, Tokushima University Graduate School, Tokushima, Japan; ${ }^{2}$ Student Lab, Tokushima University Faculty of Medicine, Tokushima, Japan; ${ }^{3}$ Department of Clinical Pharmacy, Institute of Biomedical Sciences, Tokushima University Graduate School, Tokushima, Japan; ${ }^{4}$ Department of Pharmacy, Tokushima University Hospital, Tokushima, Japan; ${ }^{5}$ Department of Clinical Pharmacy, Faculty of Pharmacy and Pharmaceutical Sciences, Fukuyama University, Fukuyama, Japan; ${ }^{6}$ Department of Nephrology, Institute of Biomedical Sciences, Tokushima University Graduate School, Tokushima, Japan; ${ }^{7}$ Department of Medical Pharmacology, Institute of Biomedical Sciences, Tokushima University Graduate School, Tokushima, Japan and ${ }^{8}$ Laboratory of Pharmaceutical and Medicinal Chemistry, Gifu Pharmaceutical University, Gifu, Japan

Correspondence: Y Ikeda, MD, PhD, Department of Pharmacology, Institute of Biomedical Sciences, Tokushima University Graduate School, 3-18-15 Kuramoto-cho,

Tokushima 770-8503, Japan.

E-mail: yasuike@tokushima-u.ac.jp

${ }^{9}$ These authors equally contributed to this work.

Received 19 August 2016; revised 16 January 2017; accepted 16 January 2017 
oxidative stress and transient proteinuria, tubular damage, and inflammatory cytokine production in patients with CKD. ${ }^{13,14}$ Thus, parenteral iron supplementation might aggravate and cause complications in CKD through oxidative stress production. Furthermore, iron might exacerbate erythropoietin production consequent to remnant kidney injury, however, the effect of iron on EPO regulation has not been elucidated.

Here, we demonstrate that saccharated ferric oxide (SFO) reduced renal EPO expression through iron-induced oxidative stress production-dependent inactivation of hypoxia-inducible factor- $2 \alpha$ (HIF- $2 \alpha$ ). Our findings suggest that therapeutic iron supplementation has a harmful effect on EPO regulation in remnant kidney function, causing a vicious cycle of CKD progression.

\section{MATERIALS AND METHODS Materials}

We purchased saccharated ferric oxide (SFO), cobalt chloride $\left(\mathrm{CoCl}_{2}\right)$, tempol, and dimethyloxallyl glycine (DMOG) from Nichi-Iko Pharmaceutical, Co., Ltd. (Toyama, Japan), Wako Pure Chemical Industries (Osaka, Japan), Sigma-Aldrich (St Louis, MO, USA), and Cayman Chemical Company (Ann Arbor, MI, USA), respectively. The following commercially available antibodies were used: anti-HIF- $2 \alpha$ (R\&D Systems, Minneapolis, MN, USA); anti-HIF- $1 \alpha$ (Cayman Chemical); anti-PDGF-R $\beta$ (Cell Signaling Technology, Beverly, MA, USA); anti- $\alpha$-SMA (Sigma-Aldrich, St Louis, MO, USA); anti-Lotus Tetragonolobus Lectin (VECTOR Laboratories, Burlingame, CA, USA); E-cadherin (Cell Signaling Technology); anti- $\alpha$-tubulin, as a loading control, from Calbiochem (San Diego, CA, USA).

\section{Animal Preparation and Procedure}

All experimental procedures were performed in accordance with the guidelines of the Animal Research Committee of Tokushima University Graduate School, and protocols were approved by the Institutional Review Board for animal protection. Eight-week-old C57BL/6J mice were obtained from Nippon CLEA (Tokyo, Japan) and they were maintained with free access to water and food (Type NMF; Oriental Yeast, Tokyo, Japan). The unilateral ureteral obstruction (UUO) procedure was previously described in detail. ${ }^{15}$ Our mouse model of chronic iron treatment was produced as previously described. ${ }^{12}$ Briefly, intraperitoneal SFO $(2 \mathrm{mg}$ in a volume of $200 \mu \mathrm{l}$ per $25 \mathrm{~g}$ mouse) or the same volume of vehicle was administered for five consecutive days. The mice were killed $24 \mathrm{~h}$ after the last iron treatment with an intraperitoneal injection of over-dose pentobarbital, and the kidney was removed and stored at $-80^{\circ} \mathrm{C}$ until use.

\section{Induction of Anemia by Phlebotomy}

Phlebotomy was performed for two consecutive days. Briefly, after anesthesia, approximately $400 \mu$ l blood was removed via retroorbital bleeding and was replaced by the same volume of sterile normal saline by a subcutaneous injection. Then, the mice were administered the vehicle or SFO via an intraperitoneal injection and were placed on a heating pad until full recovery. The mice were killed $24 \mathrm{~h}$ after the last phlebotomy.

\section{Cell Culture}

Although renal EPO-producing cells are suggested to be derived from tubular interstitial cells such as fibroblasts ${ }^{16,17}$ or pericytes, ${ }^{18}$ there are no cell lines established. Therefore, HepG2 cells, a human hepatoma cell line, have been used as EPO-producing cells in in vitro experiments. ${ }^{19-21}$ Similarly, we used HepG2 cells to investigate the mechanism of iron on EPO regulation in this study. HepG2 cell was purchased from the Japanese Collection of Research Bioresources (Osaka, Japan). The cells were cultured in Dulbecco's Modified Eagle's Medium (DMEM; Wako Pure Chemical Industries, Osaka, Japan) according to the protocol. For each experiment, the cells at passage 5-8 were used. The cells were grown to confluence, then transferred to serum-free medium before the start of the experiments. In some experiments, the cells were pretreated with $100 \mu \mathrm{M} \mathrm{CoCl}_{2}, 200 \mu \mathrm{M}$ DMOG, and $100 \mu \mathrm{M}$ tempol for $1 \mathrm{~h}$ before stimulation with SFO.

\section{RNA Extraction and Evaluation of mRNA Expression Levels}

RNA extraction, cDNA synthesis, and quantitative RT-PCR methods have been previously described. ${ }^{15}$ Briefly, the tissues or cells were homogenized in RNAiso reagent (Takara Bio, Otsu, Japan). RNA extraction and cDNA synthesis were performed according to the manufacturer's instructions (PrimeScript RT reagent Kit with gDNA Eraser (Perfect Real Time), Takara Bio). Quantitative RT-PCR was performed using the CFX Connect Real-Time PCR Detection System (Bio-Rad Laboratories, Hercules, CA, USA) with THUNDERBIRD SYBR qPCR Mix (TOYOBO CO., LTD., Osaka, Japan). The expression levels of all target genes were normalized using $36 B 4$ as an internal control. ${ }^{15}$ The primer sets used are noted in Table 1.

\section{Protein Extraction and Western Blot Analysis}

Protein preparation and western blotting were performed as previously described. ${ }^{15}$ Briefly, the tissues or cell samples were homogenized and sonicated, and then proteins were extracted. The extracted proteins were boiled for $5 \mathrm{~min}$ in Laemmli sample buffer and separated using SDS-PAGE. The proteins were transferred to a polyvinylidene fluoride (PVDF) membrane and the membrane was blocked for $1 \mathrm{~h}$ at room temperature. Next, the membrane was incubated individually with each primary antibody overnight at $4{ }^{\circ} \mathrm{C}$, followed by incubation for $1 \mathrm{~h}$ with the secondary antibody. Immunoreactive bands were detected using a chemiluminescence reagent and visualized by exposure onto an X-ray film or by C-DiGit chemiluminescent scanner (LI-COR C-DiGit Blot Scanner, Lincoln, NE, USA). Densitometry of the visualized bands was quantified using Image J $1.38 \times$ software. 
Table 1 Sequence of the primers for real-time PCR

\begin{tabular}{lll}
\hline Target gene & Forward (5'-3') & Reverse (5'-3') \\
\hline Mouse EPO & ATGTCGCCTCCAGATACCAC & CCTCTCCCGTGTACAGCTTC \\
Mouse HIF-2a & CTAAGTGGCCTGTGGGGAT & CGAAGTCCTTGCAGACCTC \\
Mouse HIF-1a & TCAAGTCAGCAACGTGGAAG & TATCGAGGCTGTGTCGACTG \\
Mouse VEGF & CAGGCTGCTGTAACGATGAA & GCATTCACATCTGCTGTGCT \\
Mouse PHD3 & CAGGTTATGTTCGCCATGTG & TGGCGTCCCAATTCTTATTC \\
Mouse PGK1 & GTCGTGATGAGGGTGACTT & TTGATGCTTGGACAGCAG \\
Human EPO & TCCGAACAATCACTGCTGA & CCTCCCCTGTGTSCSGCTTC \\
Human HIF-2a & TGCTGGATTGGTTCACACAT & GGGCCAGGTGAAAGTCTACA \\
Human HIF-1a & TGCTCATCAGTTGCCACTTC & TCCTCACACGCAAATAGCTG \\
Human VEGF & AAGGAGGAGGGCAGAATCAT & CACACAGGATGGCTGAAGA \\
Human PHD3 & AGATCGTAGGAACCCACACG & TTCTGCCCTTCTTCAGCAT \\
Human PGK1 & GAAGTGGAGAAAGCCTGTGC & GCATCTTTCCCTTCCCTTC \\
36B4 & GCTCCAAGCAGATGCAGCA & CCGGATGTGAGGCAGCAG \\
\hline
\end{tabular}

\section{Immunohistochemistry in the Kidney}

The extracted kidney tissues were embedded in OCT compound (Tissue-Tek, SAKURA Finetek, Tokyo, Japan) and frozen in liquid nitrogen-cold isopentane. Samples were cut into $8-\mu \mathrm{m}$ sections, dried, and fixed in $4 \%$ paraformaldehyde for $10 \mathrm{~min}$. After blocking, the tissue sections were incubated with primary antibodies at $4{ }^{\circ} \mathrm{C}$ overnight. Antibody distribution was visualized using immunofluorescence (Alexa fluor; Life Technology, Tokyo, Japan). The sections incubated without primary antibody were used as negative controls.

\section{Measurement of Tissue Iron Content}

Tissue iron content was measured using an iron assay kit according to the manufacturer's instructions (Metallo assay, Metallogenics, Chiba, Japan) as described previously. ${ }^{15,22}$ Briefly, the extracted kidney tissues were weighed and homogenized in cell lysis buffer. Non-centrifuged crude lysates were additionally sonicated, then added and mixed with $6 \mathrm{~N}$ hydrochloric acid to a final concentration of $0.05 \mathrm{M}$ at room temperature for $30 \mathrm{~min}$. After centrifugation, the supernatants were used for iron measurement. Tissue iron concentration was corrected using tissue weight and expressed as $\mu \mathrm{g}$ Fe per gram of wet tissue.

\section{Cell Viability Assay}

Cell viability was accessed using CellTiter 96 AQueous nonradioactive cell proliferation assay kit (Promega KK, Tokyo, Japan). ${ }^{23}$ Briefly, HepG2 cells were seeded in 96-well plates at $1 \times 10^{4}$ cells per well and incubated for $24 \mathrm{~h}$. Subsequently, various concentrations of SFO were added for $24 \mathrm{~h}$ and the impact of SFO on cell viability was assessed $1 \mathrm{~h}$ after the addition of MTS reagent by measuring absorbance at
$490 \mathrm{~nm}$ with a plate reader (iMARK microplate reader, Bio-Rad Laboratories).

\section{Detection of Labile Ferrous Iron}

We used RhoNox-1 to detect intracellular labile ferrous iron. RhoNox-1 was kindly provided from Dr Tasuku Hirayama and Professor Hideko Nagasawa. ${ }^{24}$ In brief, an unfixed frozen section of the kidney was washed with Hank's Balanced Salt Solution (HBSS) three times and incubated with RhoNox-1 in HBSS $(5 \mu \mathrm{M})$ in a dark, humidified container at room temperature for $30 \mathrm{~min}$. After washing with HBSS three times, the section was covered with a small drop of the mounting medium, and observed using fluorescence microscopy. In some experiments, the frozen sections were fixed in $10 \%$ neutral formaldehyde for $1 \mathrm{~min}$, washed with HBSS, and incubated with RhoNox- $1 .{ }^{25}$ Then, the sections were incubated with the primary antibody at $4{ }^{\circ} \mathrm{C}$ overnight in a dark humidified container. Lectin and E-cadherin were used as a marker of the proximal and distal tubules, respectively. In HepG2 cells, the cells were seeded in a 24-well culture plate or a black 96-well microplate. HepG2 was stimulated with SFO for $1 \mathrm{~h}$ and then loaded with $5 \mu \mathrm{M}$ RhoNox-1 in HBSS at $37^{\circ} \mathrm{C}$ for $30 \mathrm{~min}$. After washing, ferrous iron was observed using fluorescence microscopy or quantitatively measured at 530 and $575 \mathrm{~nm}$ for RhoNox-1 using a fluorescence microplate reader (Varioskan Flash, Thermo Fisher Scientific, Waltham, MA, USA).

\section{In Situ Oxidative Stress Detection in Kidney Tissue}

Detection of superoxide production in the kidney was evaluated by dihydroethidium (DHE) staining method as described previously. ${ }^{22}$ Briefly, non-fixed frozen tissue sections were incubated with DHE in PBS $(10 \mu \mathrm{M})$ in a dark, humidified container at room temperature for $30 \mathrm{~min}$ and then observed using fluorescence microscopy.

\section{Intracellular Reactive Oxidative Species Detection}

Intracellular reactive oxidative species (ROS) were detected using 2', $7^{\prime}$-dichlorofluorescin diacetate (DCFH-DA; SigmaAldrich, St Louis, MO, USA). HepG2 was stimulated with SFO for $1 \mathrm{~h}$ and then loaded with $10 \mu \mathrm{M}$ DCFH-DA at $37^{\circ} \mathrm{C}$ for $30 \mathrm{~min}$. After washing, ROS production was observed using fluorescence microscopy or quantitatively measured at 488 and $532 \mathrm{~nm}$ for DCFH-DA using a microplate reader (FilterMax F3 Multi-Mode Microplate Readers, Molecular Devices, Sunnyvale, CA, USA).

\section{Chromatin Immunoprecipitation}

Chromatin immunoprecipitation (ChIP) was performed to determine the interaction between the HIF- $2 \alpha$ protein and Epo gene promoter containing the hypoxia response element (HRE). Briefly, the HepG2 cells treated with vehicle or SFO, and with or without tempol were crosslinked with formaldehyde at a final concentration of $1.0 \%$ for $10 \mathrm{~min}$, then added to $2.5 \mathrm{mM}$ glycine to stop the crosslinking reaction. Then, 
cells were collected, incubated with cell lysis buffer, and the nuclear fraction was extracted. After sonication and centrifugation, the supernatant fraction was co-immunoprecipitated with HIF- $2 \alpha$ protein using agarose beads (Protein A/G plus-Agarose, Santa Cruz Biotechnology). The beads were washed and incubated at $65^{\circ} \mathrm{C}$ in elution buffer to reverse the cross-links. DNA was purified from the elution buffer and used for PCR. The primer sequence for the HRE-containing region of the human EPO promoter was used as shown previously. ${ }^{26}$ The primer sequences, used to amplify the
HRE-containing region of the human $E P O$ promoter were as follows: EPO forward primer $5^{\prime}$-TCGTTTTCTGGGAAC CTCCA-3', and EPO reverse primer 5'-GGAGCCACC TTATTGACCAG-3'.

\section{Hypoxia-Responsive Element Luciferase Reporter Assay}

The hypoxia-responsive reporter vector was constructed using three tandem copies of the HRE from the human $E P O$ gene subcloned into the secreted luciferase from the marine copepod Metridia longa transcription unit a

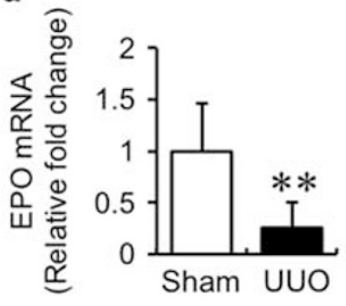

C

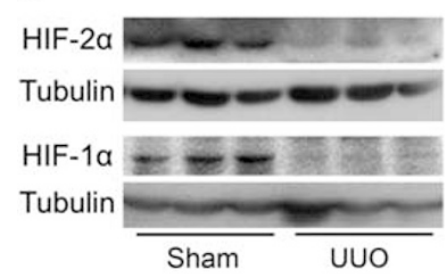

d

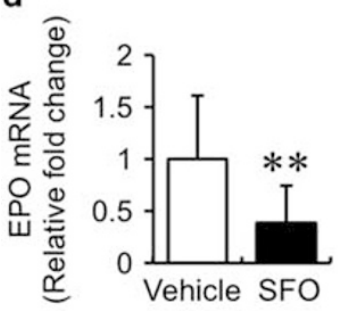

f

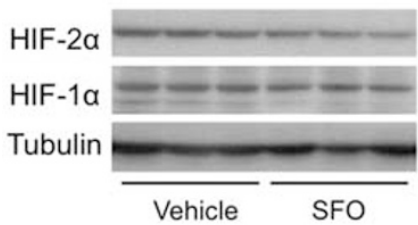

b
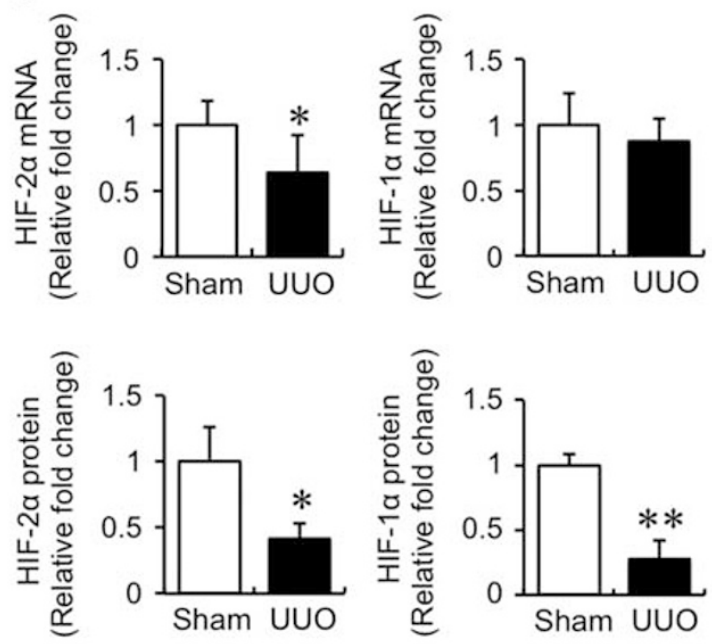

e
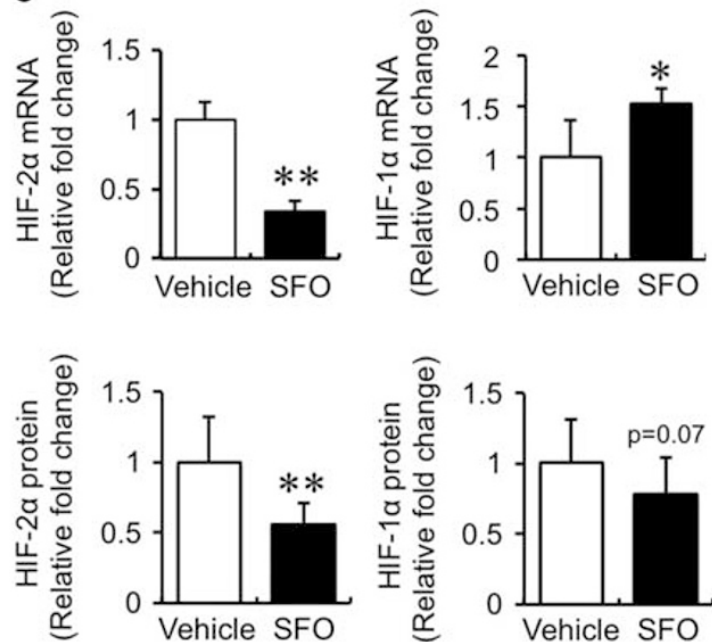

Figure 1 Expression of erythropoietin (EPO) and hypoxia-inducible factors (HIFs) in kidneys with unilateral ureteral obstruction (UUO) and iron treatment. (a) Changes in EPO mRNA expression from kidney of sham-operated or UUO mice at day 7. Quantitative real-time reverse transcriptasepolymerase chain reaction (qRT-PCR) analysis of EPO mRNA expression. The values are expressed as means $\pm s . d$. ${ }^{* *} P<0.01$ vs sham operation; $n=12$ in each group. (b) qRT-PCR analysis of HIF-2a and HIF-1a mRNA expression. The values are expressed as means $\pm \mathrm{s} . \mathrm{d}$. ${ }^{* *} P<0.05$ vs sham operation; $n=12$ in each group. (c) Left panels; representative figures of HIF-2a and HIF-1a from kidney at 7 days after sham operation or UUO. Right panel: semiquantitative analysis of densitometry for HIF- $2 a$ and HIF- $1 a$ protein expression. The values are expressed as means $\pm s . d$. ${ }^{*} P<0.05,{ }^{*} P<0.01$ vs sham operation; $n=3$ in each group. (d) Changes in EPO mRNA expression from kidney of vehicle- or SFO-treated UUO mice. qRT-PCR analysis of EPO mRNA expression. The values are expressed as means \pm s.d. ${ }^{* *} P<0.01$ vs vehicle; $n=11-13$. (e) qRT-PCR analysis of HIF-2 $a$ and HIF-1 $a$ mRNA expression. The values are expressed as means \pm s.d. ${ }^{*} P<0.05$, ${ }^{* *} P<0.01$ vs vehicle treatment; $n=11-13$ in each group. (f) Left panels; representative figures of HIF-2a and HIF-1 $a$ from kidney with vehicle or iron treatment. Right panel: semi-quantitative analysis of densitometry for HIF-2a and HIF-1a protein expression. The values are expressed as means \pm s.d. ${ }^{* *} P<0.01$ vs vehicle treatment; $n=12$ in each group. 
(pCre-MetLuc2-Reporter plasmid vector, Takara Bio, Shiga, Japan). One hundred nanograms pCre-MetLuc-HRE plasmid vector and $10 \mathrm{ng}$ pSEAP2-Control plasmid vector (Takara Bio) were co-transfected in $1 \times 10^{4}$ HepG2 cells using Lipofectamine 2000 (Thermo Fisher Scientific) in a 96-well culture plate. The transfected cells were exposed to the vehicle or SFO for $24 \mathrm{~h}$ and then the cell culture medium was harvested and both luciferase and alkaline phosphatase (ALP) activities were measured using Secreted Luciferase Reporter Assay (Takara Bio) and SEAP Reporter Gene Assay (SigmaAldrich Japan K.K., Tokyo, Japan), respectively, according to the manufacturer's instructions. To normalize the transfection efficiency, the RLU of the luciferase chemiluminescence unit was divided by that of the ALP chemiluminescence unit.

\section{Measurement of Plasma EPO Concentration}

Plasma EPO concentration was determined by using an ELISA kit, according to the manufacturer's instructions (Mouse Erythropoietin Quantikine ELISA Kit, R\&D systems, Minneapolis, MN, USA).

\section{Statistical Analysis}

The data are presented as mean \pm s.d. An unpaired, two-tailed Student's $t$-test was used for comparison between the two groups. For comparisons between more than two groups, the statistical significance of each difference was evaluated by post hoc test using Dunnett's method or Tukey-Kramer's method. Statistical significance was indicated by $P<0.05$.

\section{RESULTS EPO Expression and Iron Content in The Kidney with UUO surgery}

$E P O$ mRNA levels are drastically reduced in kidneys with UUO surgery. ${ }^{17}$ Similarly, EPO mRNA expression was decreased in the kidney at 7 days after UUO surgery compared with sham operation (Figure 1a). We have already demonstrated that renal iron content was significantly augmented in UUO-induced fibrotic kidney in the previous study. ${ }^{15}$

\section{EPO Expression and Iron Content in the Kidney of Iron- Treated Mice}

To examine direct action of iron on EPO expression, we used mice with SFO treatment. Renal iron content was significantly increased in mice with SFO treatment for consecutive five days compared with vehicle-treated mice (vehicle; $12.0 \pm 3.6 \mu \mathrm{g}$ Fe per gram of wet tissue, SFO; $20.8 \pm 4.2 \mu \mathrm{g}$ Fe per gram of wet tissue, $n=3, P<0.05)$. EPO mRNA expression was decreased in the kidney of SFO-treated mice compared with vehicle-treated mice (Figure 1d). Similarly, the plasma EPO concentration was also suppressed in SFOtreated mice (Table 4). There were no significant differences in hematological parameters of red blood cells between vehicle- and SFO-treated mice (Table 2).
Table 2 Hematological characteristics

\begin{tabular}{lccccc}
\hline & $\begin{array}{c}\mathrm{RBC} \\
\left(\times 10^{4} / \mu \mathrm{l}\right)\end{array}$ & $\mathrm{Hb}(\mathrm{g} / \mathrm{dl})$ & $\mathrm{Ht}(\%)$ & WBC $(/ \mu \mathrm{ll})$ & $\begin{array}{c}\text { Platelet } \\
\left(\times 10^{4} / \mu \mathrm{ll}\right)\end{array}$ \\
\hline Vehicle & $870 \pm 50$ & $13.2 \pm 0.9$ & $40.7 \pm 2.2$ & $4575 \pm 340$ & $58.4 \pm 3.2$ \\
SFO & $828 \pm 54$ & $12.6 \pm 0.9$ & $38.9 \pm 2.7$ & $7623 \pm 684^{* *}$ & $45.6 \pm 7.9^{*}$
\end{tabular}

Data are means \pm s.d; $n=4 ;{ }^{*} P<0.05,{ }^{* *} P<0.01$ vs vehicle-treated mice.

\section{HIF-2a Expression in the Kidney with UUO and Iron-Treated Mice}

HIF- $2 \alpha$ is an important regulator of EPO expression in the kidney ${ }^{27}$ and liver. ${ }^{26}$ HIF- $2 \alpha$ expression was diminished in the kidneys with UUO and iron treatment compared with the kidneys with sham or vehicle treatment (Figure 1c and f). These findings suggest that iron accumulation suppresses renal EPO expression through the inhibition of HIF-2 $\alpha$. In contrast, HIF- $1 \alpha$ mRNA was not changed and HIF- $1 \alpha$ protein was decreased in the kidney of UUO mice (Figure $1 b$ and c), whereas HIF- $1 \alpha$ mRNA was elevated and HIF- $1 \alpha$ protein tended to decrease in the kidney of SFO-treated mice (Figure le and $\mathrm{f}$ ).

\section{SFO Action on Transition of Fibroblast to Myofibroblast in Kidneys}

$E P O$ production occurs in fibroblasts, and loss of EPO production occurs during the transition of fibroblast to myofibroblast in the course of renal fibrosis progression. ${ }^{16,17}$ The fibroblast to myofibroblast transition has an important role in the process of renal fibrosis. ${ }^{28}$ Therefore, we checked whether iron was involved in the fibroblast to myofibroblast transition-dependent loss of EPO production. No apparent parenchymal damages were seen in the kidney of SFO-treated mice compared with vehicle-treated mice (Figure 2a). SFO treatment augmented the expression of PDGF-R $\beta$ and $\alpha$-SMA proteins in the kidney, compared with vehicle treatment (Figure $2 \mathrm{~b}$ and $\mathrm{c}$ ). Immunohistochemical analysis showed that PDGF-R $\beta$ expression was increased in the renal interstitium of SFO-treated kidneys. The $\alpha$-SMA expression also increased in the renal interstitium of SFO-treated kidneys. In contrast, it was almost completely localized in vessels in vehicle-treated kidneys. Moreover, PDGF-R $\beta$ and $\alpha$ SMA expression were colocalized in the renal interstitium of SFO-treated kidneys (Figure 2d). These results suggest that iron-induced EPO reduction occurs due to an induction of renal fibrotic change and the myofibroblast transition.

\section{The Effect of SFO on EPO mRNA Expression in HepG2 Cells}

First, we performed the MTS cell proliferation assay to determine the effect of SFO on the viability of HepG2 cells. SFO had no effect of cellular viability at 50,100 , and $200 \mu \mathrm{g} / \mathrm{ml}$ but significantly reduced cell viability at $1000 \mu \mathrm{g} / \mathrm{ml}$. This result indicates that high concentrations of SFO are toxic for HepG2 
a

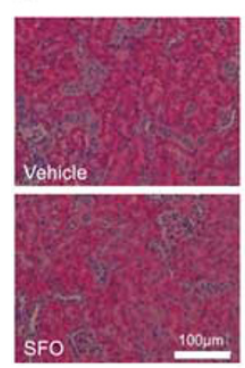

b
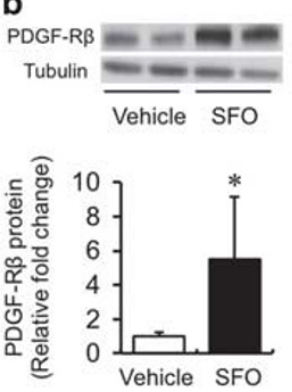

C

$\alpha-S M A$

Tubulin
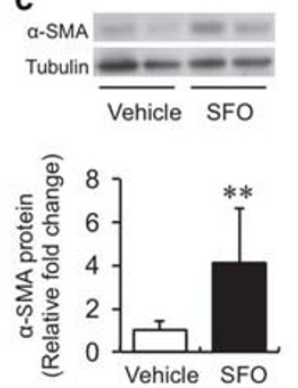

d
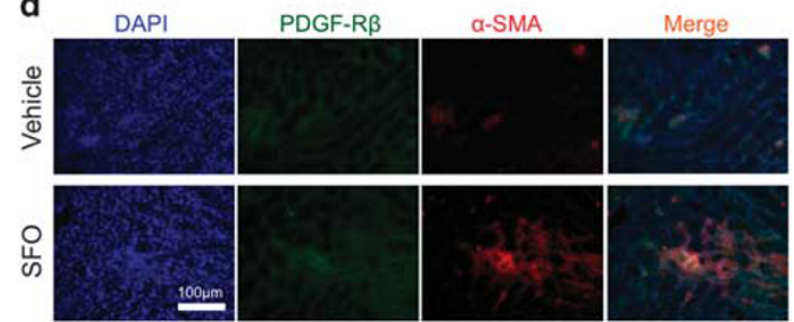

g
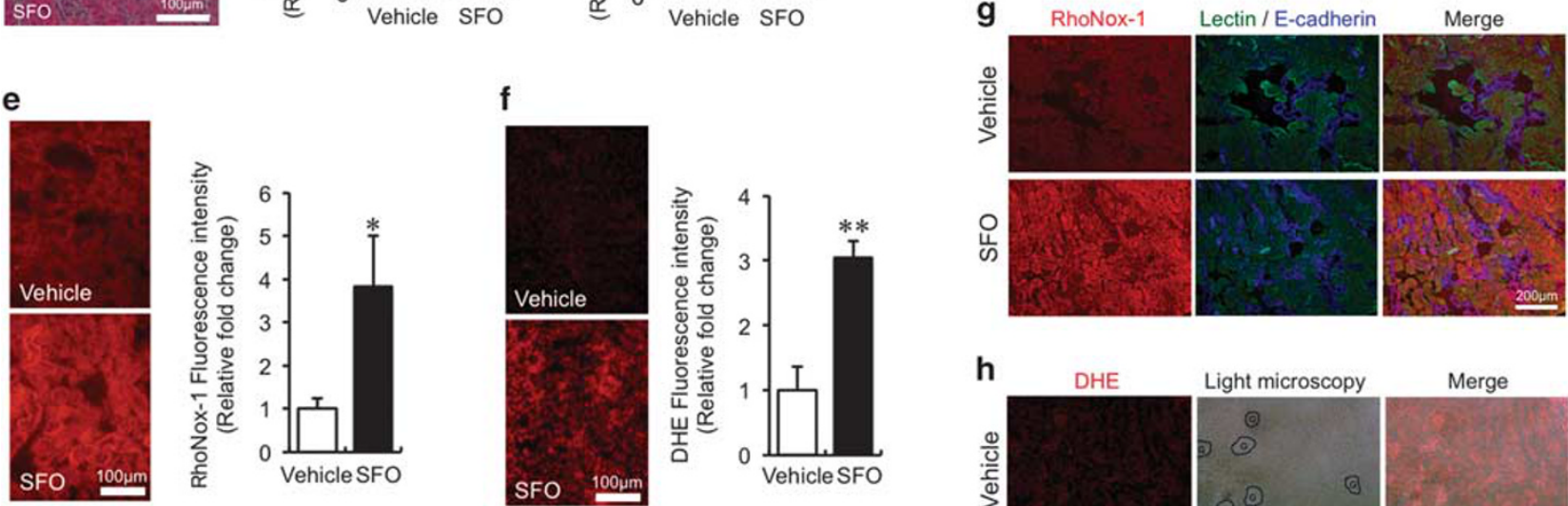
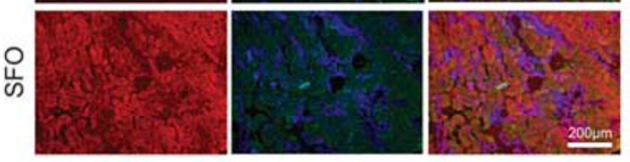

h
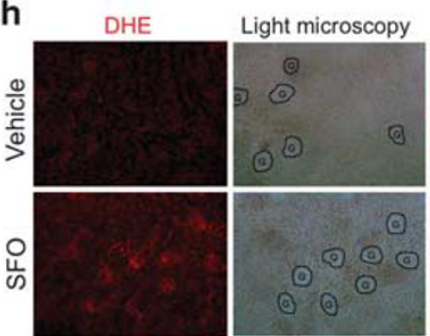

Merge

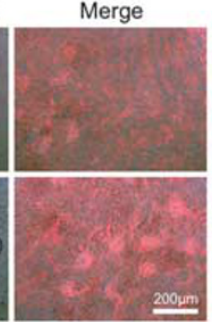

Figure 2 (a) Representative hematoxylin and eosin staining of the kidney section. (b) Western blot analysis showing the effects of iron on PDGF-R $\beta$ and a-SMA expression in kidney. Upper panels; representative figures of PDGF-R $\beta$ from kidney with vehicle or SFO treatment. Lower panel: semi-quantitative analysis of densitometry for PDGF-R $\beta$ expression. The values are expressed as means \pm s.d. ${ }^{*} P<0.05$ vs vehicle treatment; $n=8$ in each group. (c) Upper panels; representative figures of $a$-SMA from the kidney with vehicle or SFO treatment. Lower panel: semi-quantitative analysis of densitometry for $a$ SMA expression. The values are expressed as means \pm s.d. ${ }^{* *} P<0.01$ vs vehicle treatment; $n=4$ in each group. (d) Iron-induced transition from fibroblast to myofibroblast in kidney. Representative immunohistochemistry of DAPI (blue), PDGF-R $\beta$ (green), and $a$-SMA (red) staining. (e) SFO-increased labile ferrous iron in the kidney. Left panels; representative figures of RhoNox-1 staining in the kidney with or without SFO treatment. Right panel: semiquantitative analysis of fluorescence intensity. The values are expressed as means \pm s.d. ${ }^{*} P<0.05$ vs vehicle treatment; $n=4$ in each group. (f) Ironinduced oxidative stress production in the kidney. Left panels; representative figures of dihydroethidium (DHE) staining in kidney with or without SFO treatment. Right panel: semi-quantitative analysis of fluorescence intensity. The values are expressed as means \pm s.d. ${ }^{* *} P<0.01$ vs vehicle treatment; $n=3$ in each group. (g) Fluorescence image of lectin (green), E-cadherin (blue), RhoNox-1 (red), and merged image of the same field of the kidney section.

(h) Fluorescence and light microscope images of DHE staining, and merged image of the same field of the kidney section. G, glomeruli.

cells (Figure 3a). Therefore, we used SFO at concentrations of $200 \mu \mathrm{g} / \mathrm{ml}$ and below in further studies. To examine the effect of SFO on EPO regulation, we examined EPO mRNA expression after treatment with various concentration of SFO. As shown in Figure 3b, SFO significantly reduced EPO mRNA expression in a dose-dependent manner. HIF- $2 \alpha$ mRNA and protein levels were also reduced by SFO treatment in HepG2 cells (Figure $3 c$ and d). Similarly, the expression of HIF- $1 \alpha$ at the mRNA and protein levels decreased in HepG2 cells (Figure $3 \mathrm{c}$ and $\mathrm{d}$ ). The results of these in vitro experiments are consistent with in vivo results demonstrating the effect of SFO on EPO and HIF-2 $\alpha$ expression in the kidney.

\section{The Suppressive Effects of SFO on $\mathrm{CoCl}_{2}$ or DMOG-induced EPO and HIF-2 $a$ Upregulation}

We examined the effects of SFO on EPO and HIF- $2 \alpha$ expression under hypoxic conditions, using cobalt chloride to mimic conditions of hypoxia induction. EPO mRNA and HIF- $2 \alpha$ protein expression were increased by cobalt chloride treatment. The hypoxia-induced increases in EPO mRNA and HIF- $2 \alpha$ protein expression were suppressed by combining SFO and cobalt chloride treatments (Figure 3e and f). DMOG is a prolyl hydroxylase inhibitor drug, and is also used for the induction of HIF expression. As observed with cobalt chloride, DMOG treatment increased EPO mRNA and HIF- $2 \alpha$ protein expression, and these increases were inhibited by concomitant SFO treatment (Figure $3 g$ and $\mathrm{h}$ ). Cobalt chloride- or DMOG-induced HIF- $1 \alpha$ protein expression was also decreased by concomitant SFO treatment (Figure $3 \mathrm{f}$ and $\mathrm{h}$ ).

\section{SFO Treatment Induced Oxidative Stress}

Excess iron causes oxidative stress by producing hydroxyl radicals via the Fenton reaction. ${ }^{29}$ SFO treatment actually 
a

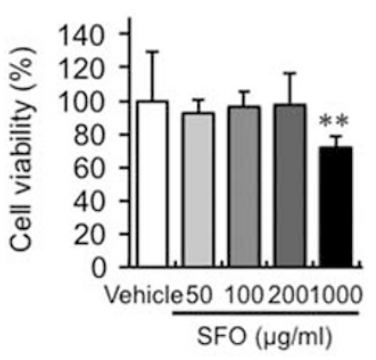

b

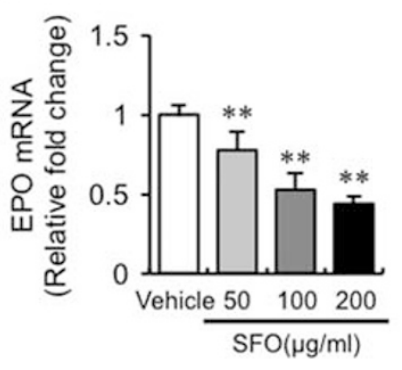

C

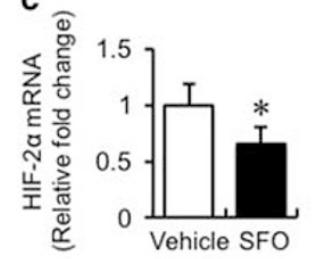

d

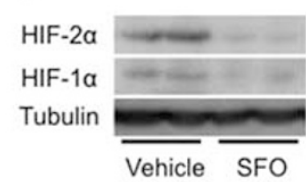

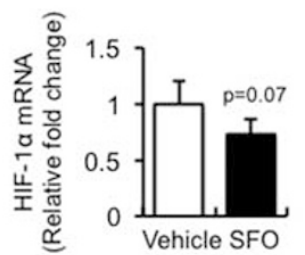
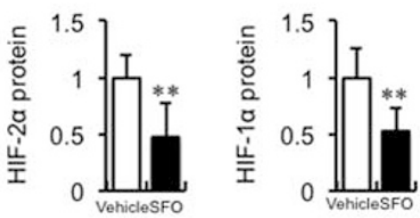

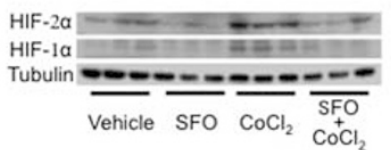

e

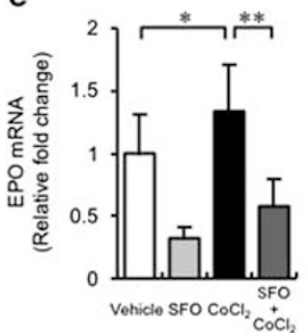

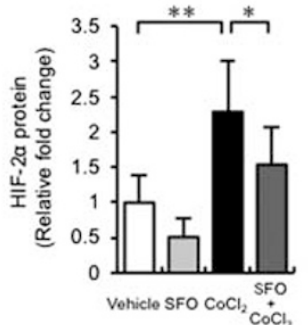

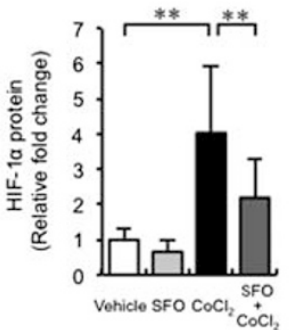

g

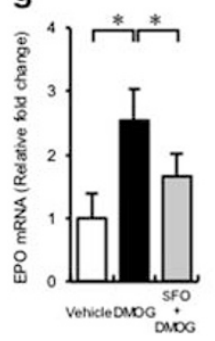

h
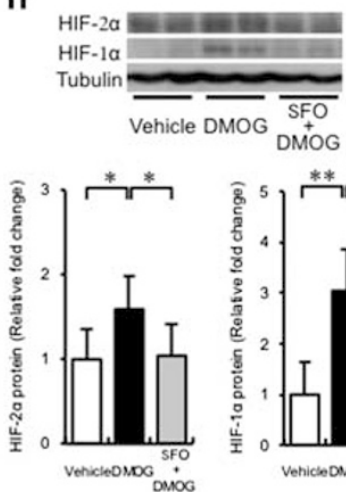

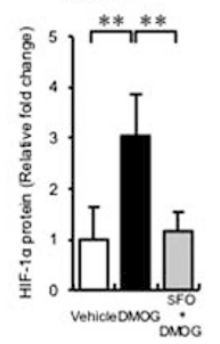

Figure 3 The effect of iron on EPO and HIFs expression in HepG2 cells. (a) HepG2 cell viability was significantly decreased only by $1000 \mu \mathrm{g} / \mathrm{ml}$ SFO treatment. The values are expressed as means \pm s.d. ${ }^{* *} P<0.01$ vs vehicle treatment; $n=8$ in each group. (b) Impact of SFO on EPO mRNA expression and dose-dependency in HepG2 cells. The values are expressed as means \pm s.d. ${ }^{*} P<0.01$ vs vehicle treatment; $n=4$ in each group. SFO action on HIFs expression in HepG2 cells. (c) Quantitative analysis of HIF- $2 a$ and HIF-1 $a$ mRNA expression. The values are expressed as means \pm s.d. ${ }^{*} P<0.05$ vs vehicle treatment; $n=6$. (d) Left panels; representative figures of HIF-2a, HIF-1a, and tubulin with vehicle or SFO treatment. Right panel: semi-quantitative analysis of densitometry for HIF- $2 a$ and HIF- $1 a$ protein expression. The values are expressed as means \pm s.d. ${ }^{* *} P<0.01$ vs vehicle treatment; $n=6$ in each group. (e) Suppressive effect of SFO on cobalt chloride-induced EPO mRNA upregulation in HepG2 cells. The values are expressed as means \pm s.d. ${ }^{*} P<0.05,{ }^{*} P<0.01$ vs vehicle treatment; $n=8$ in each group. (f) SFO suppressive action on cobalt chloride-induced upregulation of HIF- $2 a$ and HIF- $1 a$ protein expression in HepG2 cells. Upper panels; representative figures of HIF-2a, HIF-1a and tubulin. Lower panel: semi-quantitative analysis of densitometry for HIF-2 $a$ and HIF-1 $a$ expression. Values are expressed as means \pm s.d. ${ }^{*} P<0.05,{ }^{*} P<0.01$ vs vehicle treatment; $n=9$ in each group. (g) Inhibitive effect of SFO on DMOG-induced EPO mRNA upregulation in HepG2 cells. The values are expressed as means \pm s.d. ${ }^{*} P<0.05$ vs vehicle treatment; $n=4$ in each group. (h) SFO inhibitive effect on DMOG-induced upregulation of HIF-2a and HIF-1a expression in HepG2 cells. Upper panels; representative figures of HIF-2a, HIF-1 $a$ and tubulin. Lower panel: semi-quantitative analysis of densitometry for HIF-2a and HIF-1 $a$ expression. The values are expressed as means \pm s.d. ${ }^{*} P<0.05,{ }^{* *} P<0.01$ vs vehicle treatment; $n=8$ in each group.

increased labile ferrous iron mainly in both the proximal and distal tubule of the kidney (Figure 2e and g), and HepG2 cells (Figure 4a), suggesting to iron-induced oxidative stress consequent to Fenton reaction. Here, we showed that SFO induced oxidative stress in the kidney (Figure 2f). SFO-induced oxidative stress seemed to be dominantly localized in the glomeruli and a part of the proximal tubule (Figure 2h). SFO-induced oxidative stress was also observed in HepG2 cells (Figure 4b), and it was diminished by the antioxidant compound, tempol (Figure 4c). Iron content was elevated with SFO treatment, which did not change following tempol treatment (vehicle; $424 \pm 460 \mathrm{ng}$ Fe per gram protein, SFO; $9297 \pm 685 \mathrm{ng}$ Fe per gram protein, SFO+tempol; $9597 \pm 880 \mathrm{ng}$ Fe per gram protein). The suppressive effects of SFO on EPO mRNA and HIF- $2 \alpha$ protein expression, but not HIF-2 $\alpha$ mRNA, were prevented by tempol treatment (Figure $4 \mathrm{~d}-\mathrm{f}$ ). SFO-induced reduction in HIF- $1 \alpha$ protein was restored by tempol treatment (Figure $4 \mathrm{f}$ ). These findings indicate that SFO-mediated suppression of $E P O$ and HIF-2 $\alpha$ expression occurs via SFO-induced oxidative stress.

\section{SFO Suppressed the Interaction Between the HIF-2a Protein and Epo-HRE Containing Promoter}

We performed ChIP to examine the interaction between the HIF- $2 \alpha$ protein and Epo-HRE containing promoter region. As shown in Figure 4g, SFO treatment reduced HIF- $2 \alpha$ binding to the Epo promoter. The suppressive action of SFO 
a

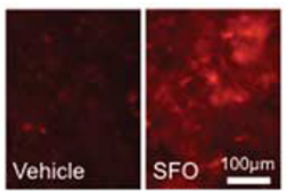

b
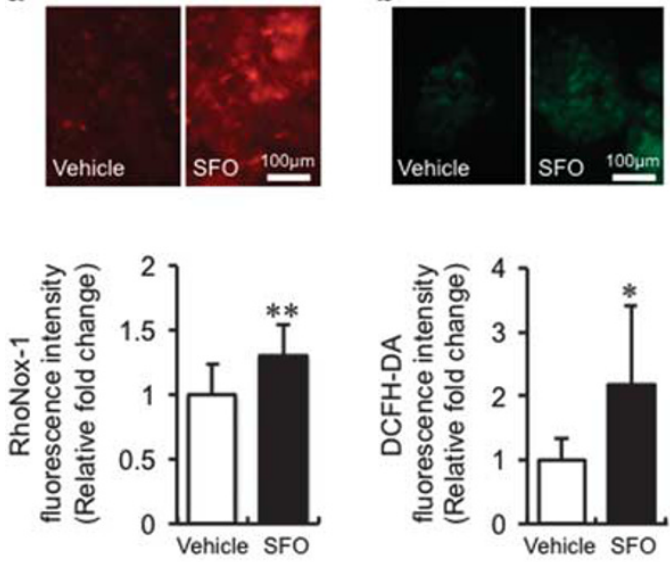

C

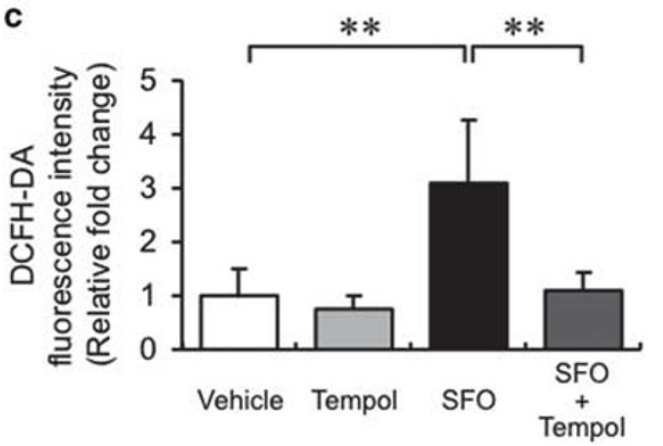

d

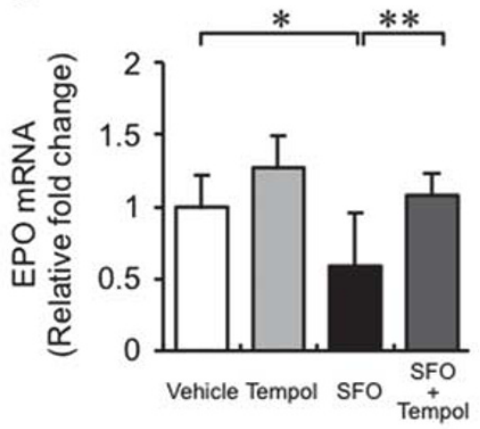

f
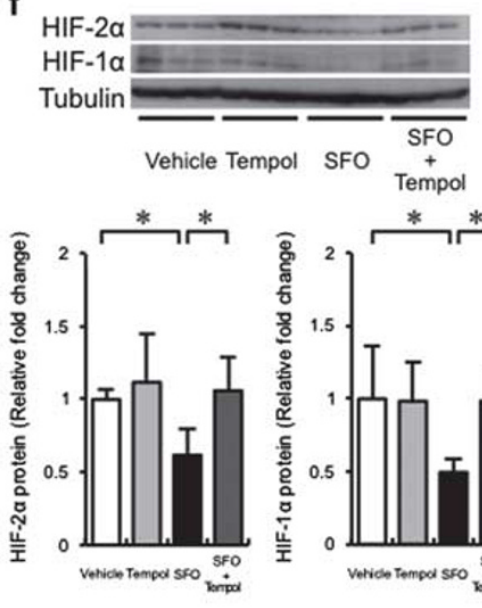

e

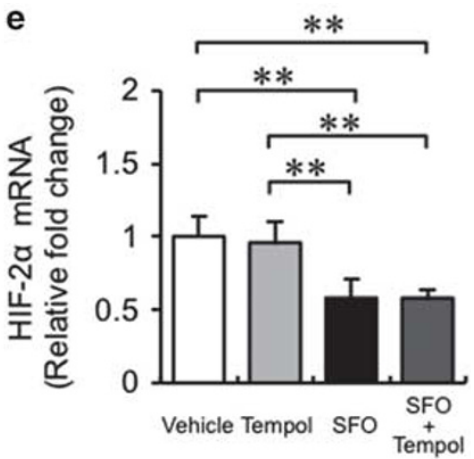

g
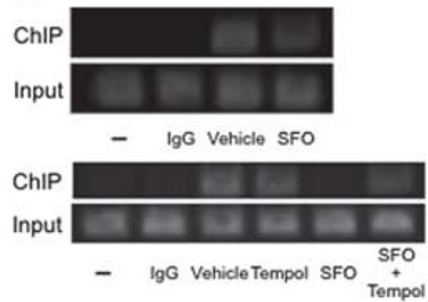

h

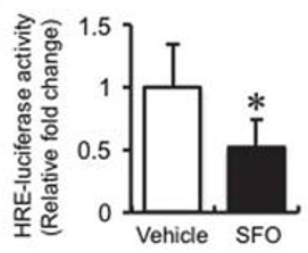

Figure 4 Involvement of oxidative stress in iron-induced downregulation of EPO and HIFs expression in HepG2 cells. (a) Upper panels; representative figures of RhoNox-1 staining in HepG2 cells with or without SFO. Lower panel: quantitative analysis of fluorescence intensity measured by microplate reader. The values are expressed as means \pm s.d. ${ }^{* *} P<0.01$ vs vehicle treatment; $n=8$ in each group. (b) Upper panels; representative figures of DCFHDA staining in HepG2 cells with or without SFO. Lower panel: quantitative analysis of fluorescence intensity measured by microplate reader. The values are expressed as means \pm s.d. ${ }^{*} P<0.05$ vs vehicle treatment; $n=16$ in each group. (c) Effect of antioxidant agent on SFO-induced oxidative stress. Quantitative analysis of DCFH-DA fluorescence intensity measured by microplate reader. The values are expressed as means $\pm s$.d. ${ }^{* *} P<0.01 ; n=16$ in each group. (d) Restorative effect of tempol on SFO-induced EPO mRNA downregulation in HepG2 cells. The values are expressed as means \pm s.d. ${ }^{*} P<0.05$, ${ }^{*} P<0.01$ vs vehicle treatment; $n=8$ in each group. (e) Tempol has no effect on SFO-induced HIF-2a mRNA downregulation in HepG2 cells. The values are expressed as means \pm s.d. ${ }^{*} P<0.01$ vs vehicle treatment; $n=8$ in each group. (f) Restorative effect of tempol on iron-induced downregulation of HIF- $2 a$ and HIF-1 $a$ expression in HepG2 cells. Upper panel: representative figures of HIF-2a, HIF-1 $a$, and tubulin. Lower panel: semiquantitative analysis of densitometory for HIF- $2 a$ and HIF- $1 a$ expression. The values are expressed as means \pm s.d. ${ }^{*} P<0.05$ vs vehicle treatment; $n=6$ in each group. (g) ChIP analysis of HIF-2a protein and the Epo HRE containing promoter interaction in HepG2 cells. Co-precipitated DNA fragments were detected by PCR using primers spanning the EPO HRE region. (h) SFO suppressed HRE-luciferase activity in HepG2 cells. The values are expressed as means \pm s.d. $* P<0.05$ vs vehicle treatment; $n=6$ in each group.

on the HIF-2 $\alpha$ and Epo gene promoter interaction was restored by tempol treatment. These results suggest that SFO-induced EPO downregulation was due to the inactivation of HIF- $2 \alpha$ binding to the Epo-HRE containing promoter region.

\section{The Promoter Activity of HRE was Inhibited by SFO Treatment in HepG2 Cells}

We also examined the effect of SFO on HRE promoter activity by luciferase assay. As shown in Figure 4h, SFO diminished the promoter activity of HRE by $50 \%$, indicating the inhibitory action of SFO on Epo through transcriptional inactivity of HIF.

\section{Effect of SFO on HIF-regulated genes}

HIF is a well-known transcriptional regulator for many genes. In addition to Epo, we assessed several HIF-regulated genes, such as Vegf, Phd3, and Pgk1. In the in vivo studies, SFO treatment elevated mRNA expression of these three genes (Figure 5a). However, only Phd3 mRNA expression was augmented by SFO treatment in HepG2 cells (Figure 5b). PHD3 has a crucial role in the regulation of HIF-2, ${ }^{30}$ indicating the involvement of iron in HIF- $2 \alpha$ regulation.

\section{Inhibitory Effect of SFO on Anemia-Induced EPO upregulation}

Finally, we examined whether SFO treatment suppresses anemia-induced EPO upregulation by using mice with 
a

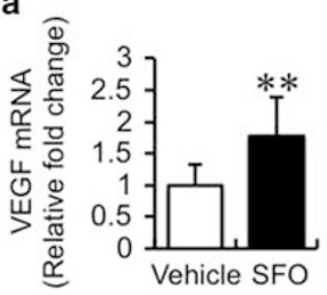

b
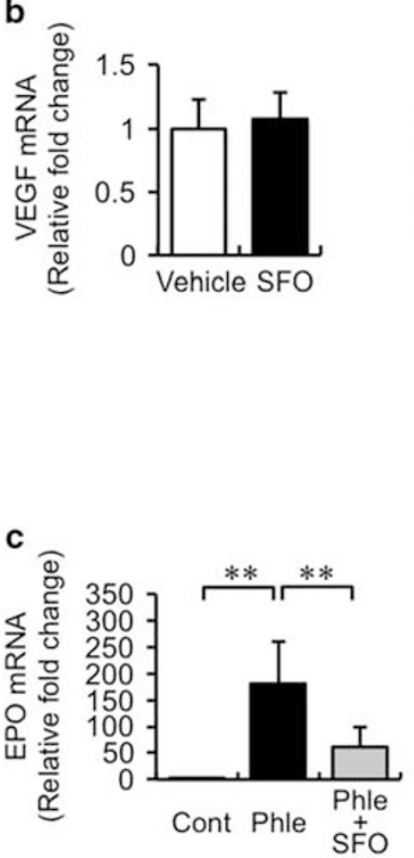
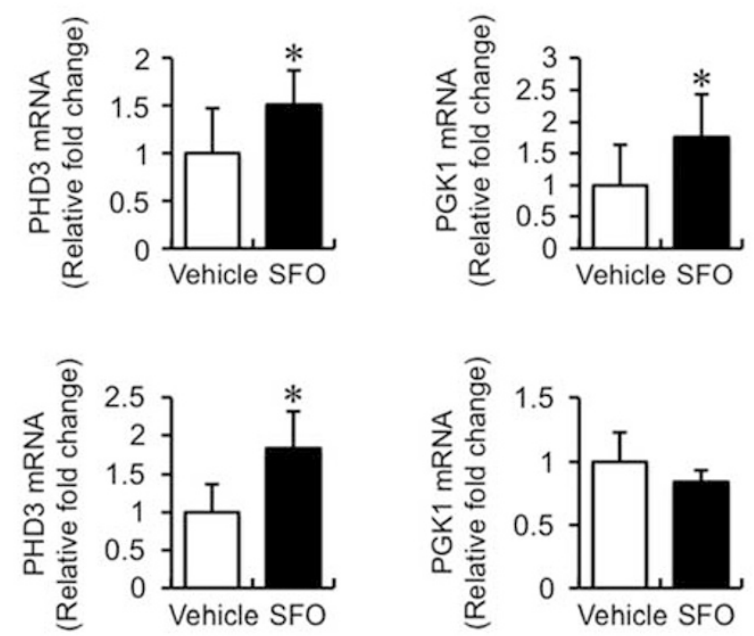

d
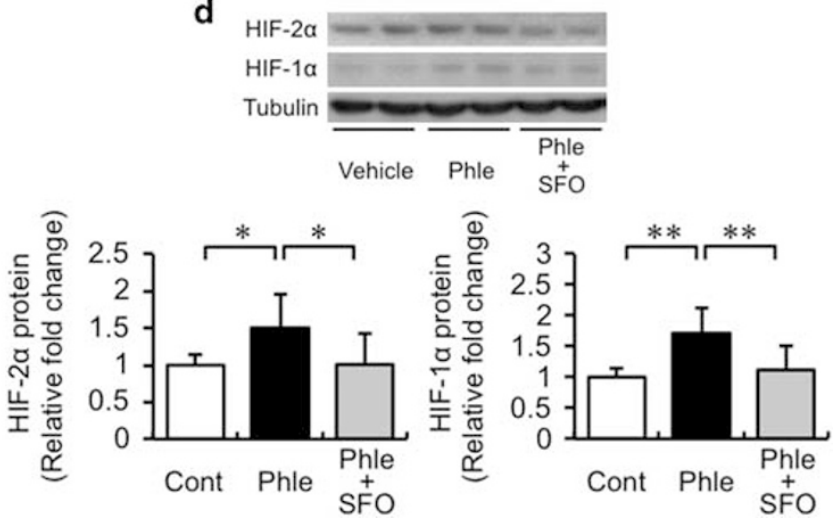

Figure 5 (a) Changes in VEGF, PHD3, and PGK1 mRNA expression in the kidney of vehicle- or SFO-treated mice. The values are expressed as means \pm s.d. ${ }^{*} P<0.05,{ }^{*} P<0.01$ vs vehicle; $n=11-13$ in each group. (b) The effect of SFO on VEGF, PHD3, and PGK1 mRNA expression in HepG2 cells. The values are expressed as means \pm s.d. ${ }^{*} P<0.05$ vs vehicle; $n=4$ in each group. Effects of SFO on (c) EPO and (d) HIFs in mice with phlebotomy-induced anemia. The values are expressed as means \pm s.d. ${ }^{*} P<0.05,{ }^{*} P<0.01$ vs vehicle; $n=7$ in each group.

Table 3 Hematological characteristics

\begin{tabular}{lccccc}
\hline & $\begin{array}{c}\mathrm{RBC} \\
\left(\times 10^{4} / \mu \mathrm{l}\right)\end{array}$ & $\mathrm{Hb}(\mathrm{g} / \mathrm{dl})$ & $\mathrm{Ht}(\%)$ & WBC $(/ \mu \mathrm{l})$ & $\begin{array}{c}\text { Platelet } \\
\left(\times 10^{4} / \mu \mathrm{l}\right)\end{array}$ \\
\hline Control & $897 \pm 39$ & $13.6 \pm 0.6$ & $40.7 \pm 1.7$ & $4367 \pm 2084$ & $54.1 \pm 3.1$ \\
Phlebotomy & $469 \pm 87^{* *}$ & $7.4 \pm 1.3^{* *}$ & $22.4 \pm 3.6^{* *}$ & $3766 \pm 1666$ & $54.1 \pm 14.7$ \\
Phlebotomy & $432 \pm 14^{* *}$ & $6.7 \pm 0.4^{* *}$ & $20.5 \pm 0.3^{* *}$ & $4600 \pm 985$ & $31.1 \pm 19.2$ \\
+SFO & & & & &
\end{tabular}

Data are means \pm s.d; $n=3 ;{ }^{* *} P<0.01$ vs control mice.

phlebotomy-induced anemia. Phlebotomy-induced anemia in mice, and no differences in hematological parameters were observed in these mice regardless of SFO treatment (Table 3). As shown in Figure 5c and Table 4, anemia induced an increase in renal Epo mRNA expression as well as plasma EPO concentration, were suppressed by SFO treatment. Moreover, anemia-induced HIF- $2 \alpha$ expression was also inhibited in SFO-treated mice with phlebotomy (Figure 5d).

\section{DISCUSSION}

In CKD, patients with renal anemia are commonly administered parenteral iron supplementation. However, iron treatment itself has adverse effects on various tissues through iron-related oxidative stress production. In the present study, we found that parenteral iron treatment reduced $E P O$ mRNA and HIF- $2 \alpha$ protein expression in the mouse kidney. Notably, iron treatment augmented oxidative stress production in both in vivo and in vitro experiments, and tempol could restore iron-induced reduction of EPO and HIF- $2 \alpha$ expression in HepG2 cells. Moreover, iron suppressed HIF- $2 \alpha$ binding to the Epo-HRE containing promoter, which was ameliorated by tempol. These results suggest that iron reduces EPO expression through HIF- $2 \alpha$ inactivation via oxidative stress production.

Renal fibrosis is an important factor in the progression of $\mathrm{CKD}$ leading to end-stage renal disease, ${ }^{31}$ and renal anemia, a 
Table 4 Plasma EPO concentration

\begin{tabular}{lccr}
\hline & Vehicle & SFO \\
\hline Plasma EPO $(\mathrm{pg} / \mathrm{ml})$ & & $151.5 \pm 44.4$ & $103.9 \pm 39.4$ \\
\hline & Control & Phlebotomy & Phlebotomy+SFO \\
\hline Plasma EPO $(\mathrm{pg} / \mathrm{ml})$ & $148.3 \pm 64.8$ & $10731.7 \pm 2366.5^{* *}$ & $8087.5 \pm 2061.3^{* *}$ \\
\hline
\end{tabular}

Data are means \pm s.d.; $n=8-12 ;{ }^{*} P<0.05$ vs vehicle-treated mice. Data are means \pm s.d.; $n=7 ;{ }^{* *} P<0.01$ vs control mice, ${ }^{\#} P<0.05$ vs phlebotomy mice.

complication of CKD, develops along with renal fibrosis. The primary cause of renal anemia is inadequate EPO production consequent to loss of renal-EPO-producing cells due to renal fibrosis. ${ }^{16}$ The murine UUO model is widely recognized to induce renal fibrosis with reduced EPO expression. Renal EPO expression is drastically reduced at day 1 or later after UUO surgery. ${ }^{17}$ In the same murine UUO model, excess iron accumulation is observed in UUO-induced fibrotic kidneys compared with those of sham-operated mice. ${ }^{15}$ In addition, we confirmed reduced EPO expression in UUO fibrotic kidneys. Consistent with the association between renal fibrosis and iron accumulation, several studies have shown that iron content is increased in fibrotic kidneys of the angiotensin II-infused rat, ${ }^{32}$ Dahl salt-sensitive rat, ${ }^{33}$ and $5 / 6$ nephrectomized rat. ${ }^{34} \mathrm{We}$, and others, have shown the antifibrotic effect of tissue iron reduction using iron chelators or iron restriction chow on the kidney. ${ }^{15,33,34}$ Here, direct SFO treatment diminished renal EPO expression in the kidney with increased iron content. Therefore, there is a close relationship between iron accumulation and renal fibrosis, resulting in the reduction of $E P O$ expression.

The EPO gene promoter contains a HRE region. HIF promotes $E P O$ transcription through binding to HRE in the Epo promoter. ${ }^{26,35}$ It has been shown that HIF-1 and HIF-2 transcriptionally regulate EPO expression. However, using renal-specific HIF- $2 \alpha$ knockout mice, it has been demonstrated that renal $E P O$ expression is predominantly regulated by HIF- $2 \alpha$ and not by HIF- $1 \alpha .{ }^{36}$ Using an siRNA approach in Hep3B cells, constituting a hepatoma cell line, ${ }^{37}$ and mice with conditional hepatic HIF- $2 \alpha$ deletion, it has been shown that EPO gene induction is largely dependent on HIF-2, not HIF-1 in the liver. ${ }^{26}$ Thus, HIF- $2 \alpha$ is recognized as a key regulator of EPO expression in both the kidney and liver.

In this study, SFO treatment reduced HIF- $2 \alpha$ expression, and HIF- $2 \alpha$ protein binding to the Epo promoter region. In addition, SFO-induced HIF- $2 \alpha$ inactivation was ameliorated by the antioxidant compound, tempol, indicating the involvement of iron-mediated oxidative stress in HIF- $2 \alpha$ regulation. HIFs are generally regulated by posttranscriptional mechanisms that determine the rate of HIF protein degradation, ${ }^{38}$ and its binding ability. ${ }^{39}$ Iron itself is shown to antagonize HIF-mediated induction of EPO gene expression induced by cobalt chloride, ${ }^{40}$ and iron supplementation reduces HIF- $1 \alpha$ expression levels even under normoxia in PC3 cells. ${ }^{41}$ This is the first study to describe the association between iron and HIF- $2 \alpha$, and to suggest that the preventive action of iron on EPO expression is mediated through a HIF- $2 \alpha$-dependent signaling pathway. Prolyl hydroxylase domain (PHD) also has a crucial role in regulating HIF protein stability, and PHD activity is stimulated by ferric iron, and suppressed by iron chelation. ${ }^{42}$ Correspondingly, DMOG, a PHD inhibitor, induced EPO expression, which was also attenuated by concomitant SFO treatment in HepG2 cells. In addition, PHD3 is known to be a regulator of HIF- $2,{ }^{30}$ and SFO increased Phd3 mRNA expression in both the kidney and HepG2 cells, indicating the involvement of iron-induced PHD3 upregulation in HIF- $2 \alpha$ reduction. Therefore, SFO-mediated EPO reduction might be involved in the destabilization of HIF- $2 \alpha$ protein via the restoration of DMOG-inhibited PHD activity. In contrast to phd3 mRNA expression, mice with SFO treatment showed increased mRNA expression of Vegf and PGK1 and these genes were not changed in HepG2 cells with SFO treatment. The different expression of HIF-regulated genes induced by iron might be due to tissue or cell from different organ.

Oxidative stress is proposed to participate in regulating the protein stability and transcriptional activity of HIF. $\mathrm{H}_{2} \mathrm{O}_{2}$ destabilizes HIFs protein under hypoxia. ${ }^{43,44}$ Oxidative stresses such as diamide, $\mathrm{N}$-ethylmaleimide, and $\mathrm{H}_{2} \mathrm{O}_{2}$ also inhibit the DNA binding activity of HIF- $1 .{ }^{39} \mathrm{H}_{2} \mathrm{O}_{2}$ suppresses hypoxia-induced EPO production in HepG2 cells, ${ }^{45}$ which might be due to oxidative stress-mediated HIF inactivation. Taken together, iron-induced oxidative stress could be responsible for protein stabilization and DNA binding activity of HIF. Moreover, tempol ameliorated SFO-induced inhibition of the HIF- $2 \alpha$-EPO signaling pathway without affecting intracellular iron content. Therefore, concomitant treatment of antioxidant drugs might be effective for reducing the oxidative stress induced by iron supplementation.

HIF proteins are involved in the post-transcriptional regulation of protein expression and activity as well as the regulation of mRNA transcription. Page et al. ${ }^{46}$ have shown that HIF- $1 \alpha$ expression is increased by angiotensin II via diacylglycerol-sensitive protein kinase C-dependent transcriptional regulation in addition to the ROS-phosphatidylinositol 3-kinase pathway-dependent translational pathway. A recent study has shown that mice deficient in iron-regulatory protein 1 exhibit HIF- $2 \alpha$ protein accumulation due to de-repression of HIF-2 $\alpha$ mRNA and induce renal EPO expression. ${ }^{47}$ However, inconsistent with the above results, we have shown that SFO treatment decreased HIF- $2 \alpha$ mRNA expression in mice kidney and HepG2 cells, indicating that iron negatively regulates HIF-2 $\alpha$ expression at the transcriptional level in this study. Moreover, SFO-induced HIF- $2 \alpha$ mRNA downregulation was not changed by tempol treatment, even though SFO-mediated HIF- $2 \alpha$ protein downregulation was reversed. This suggests that iron transcriptionally regulates HIF- $2 \alpha$ expression independent of iron-mediated oxidative stress, in 
addition to the post-transcriptional regulation of protein degradation and the DNA binding activities of HIF- $2 \alpha$. Further studies are necessary to clarify the mechanism of iron regulation on HIF- $2 \alpha$ activation.

Recent studies demonstrate that renal EPO production cells are derived from fibroblasts, and the transition of fibroblast to myofibroblast is the main cause of renal fibrosis ${ }^{28}$ and loss of EPO production in CKD. ${ }^{16,17}$ We previously reported that the UUO-induced increase of $\alpha$-SMA expression in the interstitium was reduced by iron chelation. ${ }^{15}$ This indicates that iron participates in the myofibroblast transition during the process of renal fibrosis. Here, we also found that PDGF-R $\beta$ (a fibroblast marker) and $\alpha$-SMA (a myofibroblast marker) expression were enhanced, and that PDGF-R $\beta$ and $\alpha$-SMA were colocalized in the tubulo-interstitium in kidneys with SFO treatment. These findings suggest that iron promotes renal fibrotic change with transition of fibroblasts to myofibroblasts, in part leading to an iron-induced reduction of $E P O$ expression. In contrast, superoxide, as well as ferrous iron, was not observed in the renal tubulo-interstitium. Therefore, further studies are required to clarify the interaction between fibroblast, oxidative stress, and iron in the kidney.

In the present study, SFO-treated mice showed the reduced plasma EPO concentration and the lower level of RBC, $\mathrm{Hb}$, and $\mathrm{Ht}$ compared with vehicle-treated mice, suggesting the decrease of erythropoiesis due to iron-induced reduction of EPO production. On the other hand, WBC counts were elevated by SFO treatment. Intravenous iron treatment induces protein oxidation, which positively correlates to CRP levels in hemodialysis patients, ${ }^{48}$ indicating the association between iron-induced oxidative stress and inflammation. Therefore, iron treatment perhaps causes inflammation as well as oxidative stress, resulting in the increased number of WBC.

In regard to mice model of UUO, HIF- $1 \alpha$ mRNA was not changed and HIF- $1 \alpha$ protein was diminished in UUO kidney at day 7 after surgery in our study. Souma et al. ${ }^{17}$ demonstrate that HIF- $1 \alpha$ mRNA was increased in UUO kidney at day 2 after surgery. This discrepancy of HIF- $1 \alpha$ expression might be responsible for the different sampling point after UUO induction or the discordance of protein and mRNA expression.

In conclusion, parenteral iron supplementation reduced EPO gene expression via oxidative stress-induced HIF-2 $\alpha$ inactivation. These findings suggest a new potential risk of parenteral iron supplementation and a causative role of therapeutic excess iron in the further deterioration of endogenous erythropoietin production in CKD.

Supplementary Information accompanies the paper on the Laboratory Investigation website (http://www.laboratoryinvestigation.org)

\section{ACKNOWLEDGMENTS}

This work was partly supported by JSPS KAKENHI Grant (No. 15K01716) and the grant provided The Ichiro Kanehara Foundation to YI. We appreciate the excellent technical advice by Support Center for Advanced Medical Sciences, Institute of Biomedical Sciences, Tokushima University Graduate School. We thank Editage (www.editage.jp) for English language editing.

\section{DISCLOSURE/CONFLICT OF INTEREST}

The authors declare no conflict of interest.

1. Collins AJ, Foley RN, Gilbertson DT, et al. The state of chronic kidney disease, ESRD, and morbidity and mortality in the first year of dialysis. Clin J Am Soc Nephrol 2009;4(Suppl 1):S5-S11.

2. Go AS, Chertow GM, Fan D, et al. Chronic kidney disease and the risks of death, cardiovascular events, and hospitalization. N Engl J Med 2004;351:1296-1305.

3. Levey AS. Controlling the epidemic of cardiovascular disease in chronic renal disease: where do we start? Am J Kidney Dis 1998;32(5 Suppl 3): S5-S13.

4. Astor BC, Muntner P, Levin A, et al. Association of kidney function with anemia: the Third National Health and Nutrition Examination Survey (1988-1994). Arch Intern Med 2002;162:1401-1408.

5. Paganini EP. Overview of anemia associated with chronic renal disease: primary and secondary mechanisms. Semin Nephrol 1989;9 (1 Suppl 1):3-8.

6. Kdoqi, National Kidney F. KDOQI clinical practice guidelines and clinical practice recommendations for anemia in chronic kidney disease. Am J Kidney Dis 2006;47(5 Suppl 3):S11-S145.

7. Babitt JL, Lin HY. Mechanisms of anemia in CKD. J Am Soc Nephrol 2012;23:1631-1634.

8. Nakanishi T, Kuragano T, Nanami M, et al. Importance of ferritin for optimizing anemia therapy in chronic kidney disease. Am J Nephrol 2010;32:439-446.

9. Nakanishi $T$, Hasuike $Y$, Otaki $Y$, et al. Hepcidin: another culprit for complications in patients with chronic kidney disease? Nephrol Dial Transplant 2011;26:3092-3100.

10. Zhao N, Zhang AS, Enns CA. Iron regulation by hepcidin. J Clin Invest 2013;123:2337-2343.

11. Rooyakkers TM, Stroes ES, Kooistra MP, et al. Ferric saccharate induces oxygen radical stress and endothelial dysfunction in vivo. Eur J Clin Invest 2002;32(Suppl 1):9-16.

12. Kuo KL, Hung SC, Lee TS, et al. Iron sucrose accelerates early atherogenesis by increasing superoxide production and upregulating adhesion molecules in CKD. J Am Soc Nephrol 2014;25:2596-2606.

13. Agarwal R, Vasavada N, Sachs NG, et al. Oxidative stress and renal injury with intravenous iron in patients with chronic kidney disease. Kidney Int 2004;65:2279-2289.

14. Agarwal R. Proinflammatory effects of iron sucrose in chronic kidney disease. Kidney Int 2006;69:1259-1263.

15. Ikeda Y, Ozono I, Tajima S, et al. Iron chelation by deferoxamine prevents renal interstitial fibrosis in mice with unilateral ureteral obstruction. PLoS ONE 2014;9:e89355.

16. Asada N, Takase M, Nakamura J, et al. Dysfunction of fibroblasts of extrarenal origin underlies renal fibrosis and renal anemia in mice. J Clin Invest 2011;121:3981-3990.

17. Souma T, Yamazaki S, Moriguchi T, et al. Plasticity of renal erythropoietinproducing cells governs fibrosis. J Am Soc Nephrol 2013;24:1599-1616.

18. Obara N, Suzuki N, Kim K, et al. Repression via the GATA box is essential for tissue-specific erythropoietin gene expression. Blood 2008;111:5223-5232.

19. Chiang CK, Tanaka $T$, Inagi $R$, et al. Indoxyl sulfate, a representative uremic toxin, suppresses erythropoietin production in a HIF-dependent manner. Lab Invest 2011;91:1564-1571.

20. Nagai T, Yasuoka Y, Izumi $Y$, et al. Reevaluation of erythropoietin production by the nephron. Biochem Biophys Res Commun 2014;449: 222-228.

21. Asai H, Hirata J, Hirano A, et al. Activation of aryl hydrocarbon receptor mediates suppression of hypoxia-inducible factor-dependent erythropoietin expression by indoxyl sulfate. Am J Physiol Cell Physiol 2016:310:C142-C150.

22. Ikeda $\mathrm{Y}$, Enomoto H, Tajima S, et al. Dietary iron restriction inhibits progression of diabetic nephropathy in $\mathrm{db} / \mathrm{db}$ mice. Am J Physiol Renal Physiol 2013;304:F1028-F1036. 
23. Ikeda $Y$, Hamano $H$, Satoh $A$, et al. Bilirubin exerts pro-angiogenic property through Akt-eNOS-dependent pathway. Hypertens Res 2015;38:733-740.

24. Hirayama T, Okuda T, Nagasawa H. A highly selective turn-on fluorescent probe fro iron(II) to visualize labile iron in living cells. Chem Sci 2013;4:1250-1256.

25. Mukaide T, Hattori Y, Misawa N, et al. Histological detection of catalytic ferrous iron with the selective turn-on fluorescent probe RhoNox-1 in a Fenton reaction-based rat renal carcinogenesis model. Free Radic Res 2014:48:990-995.

26. Rankin EB, Biju MP, Liu Q, et al. Hypoxia-inducible factor-2 (HIF-2) regulates hepatic erythropoietin in vivo. J Clin Invest 2007;117: 1068-1077.

27. Paliege $A$, Rosenberger $C$, Bondke $A$, et al. Hypoxia-inducible factor2alpha-expressing interstitial fibroblasts are the only renal cells that express erythropoietin under hypoxia-inducible factor stabilization. Kidney Int 2010;77:312-318.

28. Kramann R, DiRocco DP, Humphreys BD. Understanding the origin, activation and regulation of matrix-producing myofibroblasts for treatment of fibrotic disease. J Pathol 2013;231:273-289.

29. Kruszewski M. Labile iron pool: the main determinant of cellular response to oxidative stress. Mutat Res 2003;531:81-92.

30. Appelhoff RJ, Tian YM, Raval RR, et al. Differential function of the proly hydroxylases PHD1, PHD2, and PHD3 in the regulation of hypoxiainducible factor. J Biol Chem 2004;279:38458-38465.

31. Iwano $M$, Neilson EG. Mechanisms of tubulointerstitial fibrosis. Curr Opin Nephrol Hypertens 2004;13:279-284.

32. Ishizaka N, Saito K, Furuta K, et al. Angiotensin II-induced regulation of the expression and localization of iron metabolism-related genes in the rat kidney. Hypertens Res 2007;30:195-202.

33. Naito $\mathrm{Y}$, Sawada $\mathrm{H}$, Oboshi $\mathrm{M}$, et al. Increased renal iron accumulation in hypertensive nephropathy of salt-loaded hypertensive rats. PLoS ONE 2013;8:e75906.

34. Naito $\mathrm{Y}$, Fujii A, Sawada $\mathrm{H}$, et al. Association between renal iron accumulation and renal interstitial fibrosis in a rat model of chronic kidney disease. Hypertens Res 2015;38:463-470.

35. Semenza GL, Nejfelt MK, Chi SM, et al. Hypoxia-inducible nuclear factors bind to an enhancer element located $3^{\prime}$ to the human erythropoietin gene. Proc Natl Acad Sci USA 1991;88:5680-5684.
36. Kapitsinou PP, Liu $\mathrm{Q}$, Unger $\mathrm{TL}$, et al. Hepatic HIF-2 regulates erythropoietic responses to hypoxia in renal anemia. Blood 2010;116: 3039-3048.

37. Warnecke C, Zaborowska Z, Kurreck J, et al. Differentiating the functional role of hypoxia-inducible factor (HIF)-1alpha and HIF-2alpha (EPAS-1) by the use of RNA interference: erythropoietin is a HIF-2alpha target gene in Hep3B and Kelly cells. FASEB J 2004;18:1462-1464.

38. Semenza GL. HIF-1 and mechanisms of hypoxia sensing. Curr Opin Cell Biol 2001;13:167-171.

39. Wang $G L$, Jiang $B H$, Semenza GL. Effect of altered redox states on expression and DNA-binding activity of hypoxia-inducible factor 1 . Biochem Biophys Res Commun 1995;212:550-556.

40. Ho VT, Bunn HF. Effects of transition metals on the expression of the erythropoietin gene: further evidence that the oxygen sensor is a heme protein. Biochem Biophys Res Commun 1996;223: 175-180.

41. Knowles HJ, Raval RR, Harris AL, et al. Effect of ascorbate on the activity of hypoxia-inducible factor in cancer cells. Cancer Res 2003;63: 1764-1768.

42. Kaelin Jr WG, Ratcliffe PJ. Oxygen sensing by metazoans: the central role of the HIF hydroxylase pathway. Mol Cell 2008;30:393-402.

43. Huang LE, Arany Z, Livingston DM, et al. Activation of hypoxiainducible transcription factor depends primarily upon redox-sensitive stabilization of its alpha subunit. J Biol Chem 1996;271:32253-32259.

44. Wiesener MS, Turley $H$, Allen WE, et al. Induction of endothelial PAS domain protein-1 by hypoxia: characterization and comparison with hypoxia-inducible factor-1alpha. Blood 1998;92:2260-2268.

45. Fandrey J, Frede S, Jelkmann W. Role of hydrogen peroxide in hypoxia-induced erythropoietin production. Biochem J 1994;303(Pt 2): 507-510.

46. Page EL, Robitaille GA, Pouyssegur J, et al. Induction of hypoxiainducible factor-1alpha by transcriptional and translational mechanisms. J Biol Chem 2002;277:48403-48409.

47. Wilkinson N, Pantopoulos K. IRP1 regulates erythropoiesis and systemic iron homeostasis by controlling HIF2alpha mRNA translation. Blood 2013;122:1658-1668.

48. Tovbin D, Mazor D, Vorobiov M, et al. Induction of protein oxidation by intravenous iron in hemodialysis patients: role of inflammation. Am J Kidney Dis 2002;40:1005-1012. 